\title{
OPTIC RESULTS OF PRIMARY IOL IMPLANTATION IN CHILDREN OF YOUNG AGE IN PHACOASPIRATION OF DIFFERENT KINDS OF CONGENITAL CATARACTS
}

\section{N. F. Bobrova, SA. Tronina, A. N. Dembovetskaya, A. K. Zhekov}

The efficacy of primary IOL implantation in congenital cataracts phacoaspiration in infants was studied on the basis of functional results of surgical treatment research.

The received visual acuity data after congenital cataracts phacoaspiration with IOL implantation in children as a whole testify to high efficacy of implantation surgery. Lower results are revealed in monocular cataracts that make necessary the further perfection of pleoptic treatment of children with monocular pseudophakia at the stage of postoperative rehabilitation.

It is revealed, that phacoaspiration with IOL implantation during firs six month of life is mostly favourable for operative treatment from the point of view of possibility of high visual functions obtaining. Early elimination of ambyogenic factor and creation of normal optical conditions for visual analyzer development are the basic preconditions for high visual function achievement and it further development.

УДК 617.758.11: 617.726-036-053.2

\section{ОСОБЕННОСТИ РАЗЛИЧНЫХ ВИДОВ АККОМОДАЦИОННОЙ ЭЗОТРОПИИ И АККОМОДАЦИОННО-ЗРАЧКОВОЙ СИСТЕМЫ У ДЕТЕЙ}

\author{
Н. Н. Бушуева, С. В. Мартынюк, А. С. Сенякина \\ ГУ «Институт глазных болезней и тканевой терапии им. В. П. Филатова \\ НАМН Украины» г. Одесса, Украина \\ ООО «Офтальмологический санаторий «Барвинок» г. Тернополь, Украина
}

\begin{abstract}
Проведено комплексне офтальмологічне обстеження (візометрія, бінокулометрія, рефрактометрія, акомодометрія, страбометрія, дослідження конвергенції, пупілографія) у 88 хворих у віці від 6 до 18 років, які страждають рефракційною (45 дітей), нерефракційною (31 хворий) і комбінованою акомодаційною езотропією (AE) (12 хворих).

Зазначені вище види акомодаційної езотропії відрізняються один від одного за станом гостроти зору, фузійної здатності, бінокулярного зору, конвергениії. Пупілографічно встановлено, що у порівнянні зі здоровими дітьми при будь-якій формі АЕ зіниці обох очей звужені, їх реакція на світло ослаблена, значно збільшений латентний період звуження зіниць при прямій і співдружній реакціях на світло, при напруженні конвергенції. Латентні періоди розширення зіниць також збільшені після закінчення світлової стимуляції і при ослабленні конвергенції. Ми вважаємо, що такі порушення зіничних реакцій свідчать про зниження лабільності і підвищення інертності АКЗС та можливо вказують на порушення функцій стовбурових структур мозку у хворих на $A E$.
\end{abstract}

Ключевые слова: косоглазие, аккомодационно-конвергентно-зрачковая система, пупиллография, эзотропия, аккомодационная эзотропия.

Ключові слова: косоокість, акомодаційно-конвергентно-зінична система, пупілографія, езотропія, акомодаційна езотропія.

АКТУАЛЬНОСТЬ. С 70-х годов ХХ века офтальмологи выделяют следующие виды аккомодационной эзотропии (АЭ): рефракционная, нерефракционная, комбинированная и декомпенсированая $[3,4,6,7,8,9,10,11,12]$. С. В. Мартинюк, Н. В. Турчин [5] установили, что чаще наблюдаются рефракционная АЭ $(53,7 \pm 5,6) \%$ и нерефракционная АЭ $(33,7 \pm 5,3) \%$, реже - комбинированная АЭ $(8,8 \pm 3,2) \%$ и декомпенсированная $(3,8 \pm 3,2) \%$ АЭ. $\mathrm{K}$ настоящему времени изучены характер рефракции, зависимость величины угла эзотропии от расстояния, на котором находится объект фиксации, влияние на угол девиации оптической коррекции аметропии, величина индекса АK/А при различных подвидах АЭ. Малоизученным остается состояние остроты зрения, бинокулярного зрения, конвергенции и аккомодационно-конвергентно-зрачковой системы (АКЗС).

Целью исследования явилось изучение состояния зрительных функций и АКЗС у детей с наиболее распространенными видами АЭ.

(C) Н. Н. Бушуева, С. В. Мартынюк, А. С. Сенякина, 2011 
МАТЕРИАЛ И МЕТОДЫ ИССЛЕДОВАНИЯ. Под наблюдением находились 88 пациентов с АЭ в возрасте от 6 до 18 лет, из них 45 больных имели рефракционную АЭ, 31 - нерефракционную АЭ, у 12 пациентов отмечена комбинированная АЭ. Исследования включали: визометрию, определение характера бинокулярного зрения на цветотесте и синоптофоре, статическую рефрактометрию, РАА по методу А. И. Дашевского, определение ближайшей точки конвергенции, страбометрию для дали и для близи. У части больных и 9 здоровых детей проведена компьютерная пупиллография с регистрацией прямой, содружественной и конвергентно-аккомодационно-зрачковой реакций ведущего и косящего глаз до и после световой стимуляции с вычислением площади зрачка, латентного периода уменышения площади зрачка и времени задержки восстановления величины зрачков. Методика проведения пупиллографии с помощью разработанного в «ГУ ИГБ и ТТ им. В. П. Филатова АМН Украины» на аппарате «Окулограф ОК-2»<?>* (рис. 1).

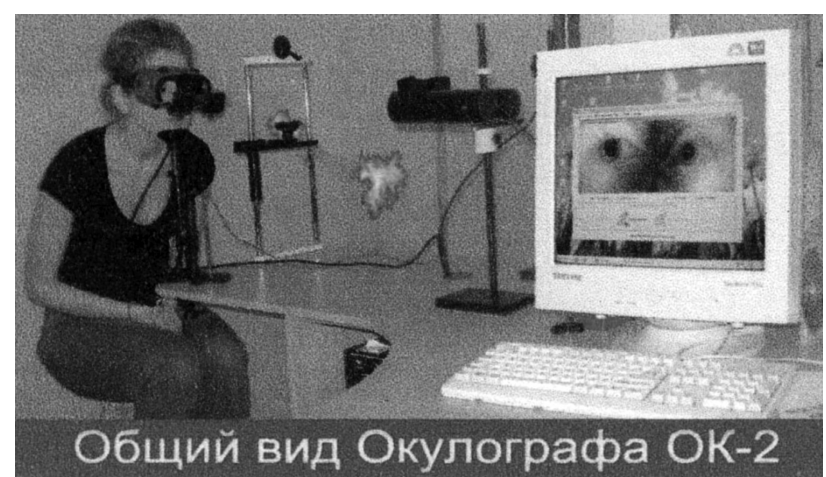

Рис. 1. Окулограф ОК-2

Технические условия для исследования прямой и содружсественной зрачковой реакции. Время непрерывной видеосъемки - 30 с. Уровень фонового освещения в помещении - 10 люкс. Время адаптации - 1мин. Освещение в области зрачков в момент засвета -20 люкс. Расстояние до источника света -100 см. Угловой размер источника света $-3^{\circ}$. Источник засвета - светодиод белого света мощностью 1 Вт с отражателями. Длительность светового стимула $-12 \mathrm{c}$.

Условия исследования реакщии зрачка при аккомодационной конвергенции. Время непрерывной видеосъемки - 30с. Уровень фонового освещения в помещении - 10 люкс; Диапазон изменения расстояния до тест-обьекта в точке ближней аккомодационной конвергенции 10 см и при взгляде вдаль - 100 см. Мощность излучения тест-объекта (источник света - светодиод) - 0,5 мВт. Длительность свечения тест-объекта в точке аккомодационной конвергенции 12 с. Исследуемый надевает маску с инфракрасными видеокамерами и фиксирует взгляд на тест-объекте, расположенном на расстоянии 100 см, который перемещается на 10 см и через 12 с. возвращается в исходное состояние. Одновременно производится видеозапись реакции зрачков. Измерение диаметра зрачка от 1,5 до 10 мм с погрешностью \pm 0,1 мм. Длительность светового воздействия от 0,1 с до 12 с с погрешностью установки $\pm 0,05$ с. Питание от сети переменного тока напряжением 220 В. Сила потребляемого тока во время съемки 5А.

Статистическая обработка данных проводилась по программе Excel-2003 [1].
РЕЗУЛЬТАТЫ И ИХ ОБСУЖДЕНИЕ. Результаты наших исследований подтвердили данные других авторов о том, что для рефракционной АЭ характерна высокая гиперметропия обоих глаз - в среднем $(5,33 \pm 0,36)$ Д для ведущего глаза и $(6,07 \pm 0,32)$ Д для косящего глаза. При нерефракционной АЭ величина гиперметропии была наименьшей: в среднем $(2,52 \pm 0,39)$ Д на ведущих глазах и $(3,51 \pm 0,40)$ Д на косящих. При комбинированной АЭ преобладала гиперметропия средней степени: $(3,93 \pm 0,56)$ Д на ведущих и $(4,32 \pm 0,64)$ Д на косящих глазах. У всех детей величина гиперметропии косящих глаз была больше, чем ведущих. У большинства из них степень анизометропии была небольшой - в пределах 0,75-2,0 Д. Наибольшая анизометропия отмечена у больных с нерефракционной АЭ - в среднем $(1,16 \pm 0,17)$ Д и рефракционной АЭ - в среднем $(0,92 \pm 0,13)$ Д, наименьшей - у пациентов с комбинированной АЭ - $(0,53 \pm 0,20)$ Д. Анизометропия от 2,25 до 4,0 Д имелась у $(18,4 \pm 7,5) \%$ больных рефракционной АЭ и у $(6,9 \pm 3,9) \%$ больных с нерефракционной АЭ.

Оптическая коррекция линзами convex sphere устраняла угол косоглазия у всех обследованных нами больных. Без оптической коррекции угол косоглазия для дали и для близи у больных с рефракционной АЭ был одинаковым - от $8^{\circ}$ до $20^{\circ}$, в среднем $(13,09 \pm 0,59)^{\circ}$. У больных с нерефракционной АЭ при фиксации взгляда вдаль девиация отсутствала, а при фиксации вблизи появлялась эзотропия от $5^{\circ}$ до $30^{\circ}$, в среднем $(11,81 \pm 0,59)^{\circ}$. Девиация у больных с комбинированной АЭ для близи была в пределах $15-30^{\circ}$ в среднем $(22,14 \pm 1,71)^{\circ}$, а для дали уменьшалась, в среднем $(13,29 \pm 1,45)^{\circ}$.

С коррекцией аметропии острота зрения ведущего глаза была нормальной у больных с нерефракционной и комбинированной, ниже у больных рефракционной АЭ. Острота зрения косящего глаза у большинства больных нерефракционной $(74,1 \pm 8,4) \%$, реже у больных рефракционной $(55,9 \pm 7,6) \%$ и комбинированной АЭ $(42,8 \pm 18,7) \%$ была нормальной, либо имела место амблиопия легкой степени. Амблиопия средней степени установлена при рефракционной АЭ у $(30,2 \pm 7,0) \%$ глаз, при нерефракционной у $(14,8 \pm 6,8) \%$ глаз, при комбинированной АЭ у $(42,9 \pm 18,7) \%$ глаз. Амблиопия высокой степени отмечена лишь у единичных больных с любым видом АЭ. Неблагоприятная для нормального бинокулярного зрения острота зрения (ниже 0,3) имела место у $(55,8 \pm 7,6) \%$ больных с рефракционной, у $(33,3 \pm 9,1) \%$ нерефракционной и у $(42,0 \pm 18,7) \%$ при комбинированной АЭ.

При любом виде АЭ резервы аккомодации обоих глаз, особенно косящего, были низкими и не превышали 3,5 Д. Средняя величина РА равнялась: при рефракционной АЭ для ведущих глаз - $(2,15 \pm 0,33)$ Д, для косящих - $(1,43 \pm 0,28)$ Д; при нерефракци- 
онной АЭ для ведущих глаз - $(2,54 \pm 0,49)$ Д, для косящих - $(0,78 \pm 0,2)$ Д.; при комбинированной для ведущих глаз - $(0,86 \pm 0,4)$ Д, для косящих $(0,43 \pm 0,2)$ Д. Таким образом слабость аккомодации свойственна не только больным с нерефракционной, как указывал Duke-Elder A. [10], но и пациентам с другими видами АЭ.

Исследование конвергенции показало, что у всех больных с рефракционной $(100 \%)$ и нерефракционной АЭ $(96,3 \pm 3,6) \%$ эта важная для бинокулярного зрения функция была в норме. А у $(42,8 \pm 18,7) \%$ больных с комбинированной АЭ конвергенция была ослаблена.

Несмотря на установление ортотропии с оптической коррекцией, фузия отсутствовала у всех больных с комбинированной и у половины больных с рефракционной АЭ $(65,1 \pm 7,3) \%$ и нерефракционной АЭ $(51,9 \pm 9,6) \%$. Нормальная фузионная способность с амплитудой фузии от 11 до $40^{\circ}$ имела место у одной трети больных рефракционной $(30,3 \pm 7,0) \%$ и нерефракционной АЭ $(33,3 \pm 9,1) \%$, а у остальных - ширина фузии была ниже нормы. По данным цветотеста в большинстве случаев рефракционной $(88,4 \pm 4,9) \%$, нерефракционной $(66,7 \pm 17,1) \%$ и комбинированной АЭ $(85,7 \pm 13,2) \%$ имелось монокулярное зрение. Одновременное зрение выявлено у $(9,3 \pm 4,4) \%$ больных с рефракционной, $(18,5 \pm 6,8) \%$ детей с нерефракционной и у одного пациента с комбинированной АЭ $(14,3 \pm 13,2) \%$. Бинокулярное зрение по данным цветотеста отмечено у единичных больных реф- ракционной $(2,3 \pm 2,3) \%$ и нерефракционной АЭ $(14,8 \pm 6,8) \%$.

Анализ приведенных в таблице 1 результатов пупиллографии прямой и содружественной зрачковых реакций показывает, что их параметры на ведущем и косящем глазах при различных видах АЭ были почти одинаковыми. В условиях фонового освещения средние величины площади зрачка косящего глаза при прямой и содружественной зрачковых реакциях у большинства больных независимо от вида АЭ были меньше чем у здоровых. В результате засвета светодиодом 1 Вт уменьшается площадь зрачков обоих глаз у всех исследуемых лиц как при прямой, так и при содружественной реакциях. При этом средняя величина площади зрачков у больных детей при прямой реакции почти в два раза превышала этот показатель у здоровых детей, что свидетельствует об ослаблении реакции зрачков на засвет при АЭ. У больных любым видом АЭ средние величины площади зрачков обоих глаз при содружественной реакции на засвет были почти одинаковыми и не отличались статистически достоверно от аналогичных показателей у здоровых детей. Значительное удлинение (более чем в 3 раза) латентного периода при прямой и содружественной реакциях зрачков на засвет и латентного периода начала восстановления исходной (фоновой) площади зрачка свидетельствует о замедленной реакции зрачков обоих глаз на изменения освещенности и о снижении их лабильности у больных с любым видом АЭ.

Таблица 1

Параметры прямой и содружественной зрачковых реакций у детей с различными видами аккомодационной эзотропии $(\mathbf{M} \pm \mathbf{m})$

\begin{tabular}{|c|c|c|c|c|c|c|c|c|c|}
\hline \multirow{5}{*}{\multicolumn{2}{|c|}{ Параметры зрачковых реакций }} & \multirow{6}{*}{$\begin{array}{c}\begin{array}{c}\text { Вид } \\
\text { зрачковой } \\
\text { реакщии }\end{array} \\
\text { Прямая } \\
\end{array}$} & \multirow{6}{*}{$\begin{array}{c}\begin{array}{c}\text { 3доровые } \\
\text { дети }\end{array} \\
46,0 \pm 1,5 \\
\end{array}$} & \multirow{2}{*}{\multicolumn{6}{|c|}{$\begin{array}{l}\text { Дети с аккомодационной эзотропией } \\
\text { Вид аккомодационной эзотропии }\end{array}$}} \\
\hline & & & & & & & & & \\
\hline & & & & \multirow{2}{*}{\multicolumn{2}{|c|}{$\begin{array}{c}\text { Рефракционная } \\
\text { глаз }\end{array}$}} & \multirow{2}{*}{\multicolumn{2}{|c|}{$\begin{array}{c}\text { Нерефракционная } \\
\text { глаз }\end{array}$}} & \multirow{2}{*}{\multicolumn{2}{|c|}{$\begin{array}{c}\text { Комбинированная } \\
\text { глаз }\end{array}$}} \\
\hline & & & & & & & & & \\
\hline & & & & ведущий & косящий & ведущий & косящий & ведущий & косящий \\
\hline \multirow{4}{*}{ 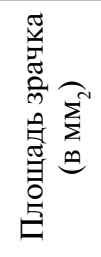 } & \multirow[b]{2}{*}{$\begin{array}{c}\text { Фоновое освеще- } \\
\text { ние (10 люкс) }\end{array}$} & & & $45,8 \pm 2,6$ & $35,2 \pm 3,5^{*}$ & $36,2 \pm 4,2$ & $28,7 \pm 4,0^{*}$ & $40,2 \pm 5,5$ & $32,6 \pm 5,1^{*}$ \\
\hline & & $\begin{array}{l}\text { Содруже- } \\
\text { ственная }\end{array}$ & 45 & $38,5 \pm 4,0$ & $3,9 *$ & $\pm 4,6$ & $31,7 \pm 5,6^{*}$ & $34,3 \pm 6,5$ & $33,5 \pm 6,4$ \\
\hline & \multirow{2}{*}{$\begin{array}{c}\text { Фоновое освеще- } \\
\text { ние в области зрач- } \\
\text { ка (20 люкс) Засвет } \\
\text { светодиод 1Вт }\end{array}$} & Прямая & $11,2 \pm 1,7$ & $21,7 \pm 7,9$ & $25,8 \pm 8,8$ & $17,8 \pm 3,2$ & $14,2 \pm 2,7^{*}$ & $24,1 \pm 6,0$ & $14,4 \pm 4,4$ \\
\hline & & $\begin{array}{l}\text { Содруже- } \\
\text { ственная }\end{array}$ & $12,1 \pm 1,7$ & $8,7 \pm 10,1$ & $12,6 \pm 3,7 *$ & $18,5 \pm 3,5$ & $13,1 \pm 3,1^{*}$ & $19,6 \pm 5,7$ & $19,4 \pm 6,2$ \\
\hline \multirow{4}{*}{ 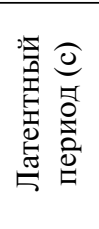 } & \multirow{2}{*}{$\begin{array}{c}\text { Реакция на засвет } \\
\text { Сужение зрачка }\end{array}$} & Прямая & $0,2 \pm 0,02$ & $3,3 \pm 2,6$ & $\pm 3,7$ & $7,8 \pm 0,9$ & $5,7 \pm 2,0$ & $6,3 \pm 2,4$ & $4,3 \pm 0,9^{*}$ \\
\hline & & $\begin{array}{l}\text { Содруже- } \\
\text { ственная }\end{array}$ & $0,2 \pm 0,02$ & $1,5 \pm 0,8$ & $1,2 \pm 0,8^{*}$ & $7,6 \pm 3,9$ & $5,8 \pm 1,3^{*}$ & $5,1 \pm 0,4$ & $4,4 \pm 2,3^{*}$ \\
\hline & \multirow{2}{*}{$\begin{array}{c}\text { Начало восстанов- } \\
\text { ления исходной } \\
\text { площади зрачка }\end{array}$} & Прямая & $0,5 \pm 0,06$ & $1,4 \pm 1,3^{*}$ & $1,4 \pm 1,3^{*}$ & $2,9 \pm 0,6^{*}$ & $2,9 \pm 0,6^{*}$ & $1,5 \pm 0,9^{*}$ & $1,5 \pm 0,9^{*}$ \\
\hline & & $\begin{array}{l}\text { Содруже- } \\
\text { ственная }\end{array}$ & $0,4 \pm$ & $4,4 \pm 3,9 *$ & $4,4 \pm 3,9 *$ & $1,9 \pm 0,2^{*}$ & $1,9 \pm 0,2^{*}$ & $2,3 \pm 0,9^{*}$ & $2,3 \pm 0,9 *$ \\
\hline
\end{tabular}

Примечание * $\mathrm{p}<0,05$ в сравнении со зрачковыми параметрами у здоровых детей

Состояние АКЗС оценивалось по величине площади зрачков и длительности латентного периода сокращения площади при переводе взгляда от
100 см до объекта, расположенного в 10 см от глаз, при котором происходит напряжение АКЗС, а также латентного периода восстановления площади 
зрачка при переводе взгляда от 10 см к 100 см, в ходе которого АКЗС расслабляется. Полученные данные приведены в таблице 2. Согласно этим данным, при расслаблении АКЗС средние величины площади зрачков обоих глаз у больных любым видом АЭ были почти в два раза меньше, чем у здоровых детей. При напряжении АКЗС у больных эти показатели почти соответствовали таковым у здоровых детей. Мы полагаем, что более узкие зрачки у больных АЭ при расслаблении АКЗС свидетельствуют о том, что АКЗС у них находится в состоянии повышенного напряжения. Средние величины латентных периодов сужения и расширения зрачков обоих глаз у больных АЭ при аккомодационно-конвергентной реакции были больше, чем у здоровых детей, что может быть вызвано снижением лабильности, заторможенностью либо повышенной инертностью AK3C.

Таблица 2

Параметры аккомодационно-конвергентно-зрачковой реакции у детей с различными видами аккомодационной эзотропии $(\mathrm{M} \pm \mathrm{m})$.

\begin{tabular}{|c|c|c|c|c|c|c|c|c|}
\hline \multirow{5}{*}{$\begin{array}{c}\text { Параметры } \\
\text { аккомодационно- } \\
\text { конвергентно-зрачковой } \\
\text { реакции }\end{array}$} & \multirow{5}{*}{$\begin{array}{l}\text { Состояние } \\
\text { АКЗС }\end{array}$} & \multirow{5}{*}{$\begin{array}{c}\text { Здоровые } \\
\text { дети }\end{array}$} & \multicolumn{6}{|c|}{ Дети с аккомодационной эзотропией } \\
\hline & & & \multicolumn{6}{|c|}{ Вид аккомодационной эзотропии } \\
\hline & & & \multirow{2}{*}{\multicolumn{2}{|c|}{$\begin{array}{c}\text { Рефракционная } \\
\text { глаз }\end{array}$}} & \multirow{2}{*}{\multicolumn{2}{|c|}{$\begin{array}{c}\text { Нерефракционная } \\
\text { глаз }\end{array}$}} & \multirow{2}{*}{\multicolumn{2}{|c|}{$\begin{array}{c}\text { Комбинированная } \\
\text { глаз }\end{array}$}} \\
\hline & & & & & & & & \\
\hline & & & ведущий & косящий & ведущий & косящий & ведущий & косящий \\
\hline \multirow{2}{*}{$\begin{array}{l}\text { Площадь зрачка } \\
\left(\text { мм²) }^{2}\right.\end{array}$} & Расслабление & $43,7 \pm 2,1$ & $27,1 \pm 2,5^{*}$ & $25,8 \pm 2,3^{*}$ & $23,3 \pm 3,3^{*}$ & $23,8 \pm 2,1^{*}$ & $28,6 \pm 3,5^{*}$ & $25,1 \pm 3,4^{*}$ \\
\hline & Напряжение & $16,5 \pm 2,8$ & $10,7 \pm 0,3$ & $9,2 \pm 2,2^{*}$ & $15,3 \pm 2,7$ & $12,1 \pm 2,2^{*}$ & $15,8 \pm 3,8$ & $14,0 \pm 3,6^{*}$ \\
\hline $\begin{array}{l}\text { Латентный период } \\
\text { сужения зрачка (c) }\end{array}$ & Напряжение & $0,5 \pm 0,1$ & $2,3 \pm 0,4$ & $2,9 \pm 0,6$ & $6,2 \pm 3,9$ & $2,3 \pm 0,7^{*}$ & $2,6 \pm 0,7$ & $2,1 \pm 0,5^{*}$ \\
\hline $\begin{array}{l}\text { Латентный период } \\
\text { расширения зрачка (c) }\end{array}$ & Расслабление & $0,8 \pm 0,1$ & $3,8 \pm 1,2^{*}$ & $3,8 \pm 1,2^{*}$ & $1,5 \pm 0,4^{*}$ & $1,5 \pm 0,4^{*}$ & $2,0 \pm 1,0^{*}$ & $2,0 \pm 1,0^{*}$ \\
\hline
\end{tabular}

Примечание * $\mathrm{p}<0,05$ в сравнении с зрачковыми параметрами у здоровых детей

\section{ЗАКЛЮЧЕНИЕ}

Наши исследования показали, что наиболее распространенные виды АЭ (рефракционная, нерефракционная, комбинированная) отличаются друг от друга по состоянию остроты зрения, фузионной способности, бинокулярного зрения, конвергенции. Выявленные нами при пупиллографии нарушения зрачковых реакций и изменения функционального состояния АКЗС могут свидетельствовать о наличии у таких больных нарушений функции стволовых структур, покрышки среднего мозга, однако это требует подтверждения в дальнейших исследованиях.

\section{ЛИТЕРАТУРА}

1. Александров А. А. Диаграммы в Exel. Краткое руководство. Диалектика. Москва. Санкт-Петербург. Киев. 2004. $-157 \mathrm{c}$.

2. Бушуева Н. Н., Бойчук И. М., Храменко Н. И. и др. Метод диагностики нарушений аккомодации на основе изучения зрачковых реакций с использованием пупиллографа// Архив клинической и экспериментальной медицины, 2001, Том 10, № 2,. С. 132- 133.

3. Дегтярева Н. М., Сердюченко В. И. Аккомодационная эзотропия: классификации, клиника, диагностика, лечение // Тези та лекції IV науково-практ. конф. дит. офтальмологів 3 міжнародною участю «Вроджена та генетично обумовлена сліпота та слабкозорість». Крим, 2009. - С. 337-343.
4. Кански Дж. Клиническая офтальмология: систематизированный подход. - М.: Логосфера, 2006. C. 516-556.

5. Мартинюк С. В. Турчин М. В. Симптоматологія різних видів акомодаційної езотропії у дітей // Матеріали XII міжнародного конгресу студентів і молодих вчених. Тернопіль: Укрмедкнига, 2008. - С. 151.

6. Пильман Н. И. Исправление косоглазия у детей. Киев: Здоров'я, 1979. - С. 18-21, 84-96.

7. Рыков С. А., Сенякина А. С. Виды косоглазия, их классификация, особенности диагностики и лечения // Тези та лекції IV науково-практ. конф. дит. офтальмологів $з$ міжнародною участю «Вроджена та генетично обумовлена сліпота та слабкозорість». Крим, 2009. - С. 323-336.

8. Сенякина А. С. Рыков С. А. К Вопросу о классификации косоглазия. // Офтальмол. журн. - 2008. № 5. - С. 62-69.

9. Сердюченко В. И., Клюка И. В., Бойчук И. М. и др. Диагностика и восстановление бинокулярного и стереоскопического зрения при типичной и атипичных формах аккомодационного сходящегося косоглазия. Методические рекомендации. - Одесса, 1992. $23 \mathrm{c}$.

10. Duke-Elder A., Abrams D. Ophthalmic Optics and Refraction. - In: Duke-Elder S. (ed): System of Ophthalmology. - St. Louis, CV Mosby, 1970. - Vol. 5. - P. 180-188.

11. Parks M: Sensorial adaptation in strabismus. In Ocular Motility and Strabismus, p 67. Hagerstown, MD, Harper \& Row, 1975.

12. Taylor D. Pediatric Ophthalmology. - Boston: Blackwall Scientific Publications, 1990. - 385c.

Поступила 13.04.2011. Рецензент д-р мед. наук. И. М. Бойчук 


\title{
PECULIARITIES OF DIFFERENT TYPES OF THE ACCOMMODATIVE ESOTROPIA AND PUPILLO-ACCOMMODATIVE SYSTEM IN CHILDREN
}

\author{
Bushuyeva N. N., Martynuyk S. V., Senyakina A. S. \\ Odessa, Ukraine
}

\begin{abstract}
Objective - the study of visual dysfunctions, ACPS in children with the most common types of AE.
Materials and Methods: A complex ophthalmological examination (visometry, binoculometry, refractometry, accommodometry, strabometry, the study of convergence, pupillography) in 88 patients aged from 6 to 18 with refractive $\mathrm{AE}$ (45 children), nonrefractive $\mathrm{AE}$ ( 31 patients) and the combinated $\mathrm{AE}$ (12 patients).

Results. Besides the already known differences in the state of refraction and the value of index AC/A, the abovementioned types of $\mathrm{AE}$ differ from each other in such functions as visual acuity, fusion power, binocular vision, convergence. Using pupillography it was found that in patients with any kind of AE both eyes' pupils were narrowed in comparison with healthy children, their reaction to light was weakened considerably. The latent periods of the pupillary light reflex and the pupillary near reflex were increased more than three times compared with healthy children. The latent periods of pupillary dilatation after light stimulation and after convergence weakening were also increased. The authors believe that such disturbances of the pupillary reactions indicate reduction of the lability, increase ACPS inactivity that indicate the functional changes in the brainstem structures of the patients with AE.
\end{abstract}

УдК 617.713-001.5-089.84

\section{ПОРІВНЯЛЬНИЙ АНАЛІЗ ЕФЕКТИВНОСТІ РІЗНИХ СПОСОБІВ ПЕРВИННОЇ ХІРУРГІЧНОЇ ОБРОБКИ ПРОНИКАЮЧИХ ПОРАНЕНЬ РОГІВКИ}

\author{
Н. Ф. Боброва, д. М. Н., проф., В. І. Шевчик, аспірант, М. П. Кульбіда, м. н. С.
}

Державна установа «Інститут очних хвороб і тканинної терапії ім. В. П. Філатова

Академії медичних наук України»

\begin{abstract}
Нами проведен сравнительный анализ ПХО проникающих ранений роговищы с использованием сквозных и несквозных роговичных швов. Изучена динамика изменений остроты зрения, развитие индуцированного астигматизма, сроки пребывания больных в стационаре, изменение площади рубиа, а также коэффициента качества формирования рубца роговицы (который определялся как соотношение длины рубца кего площади) в сроки от 3 дней до одного года после ПХО. Выявлено статистически достоверное преимущество сквозных роговичных швов с различной длиной и шагом шва перед традиционным способом с ушиванием на 2/3 глубины роговицы и одинаковыми швами по размерам и шагом шва.
\end{abstract}

Ключові слова: проникаючі поранення ока, ПХО рогівки, наскрізні шви рогівки

Ключевые слова: проникающие ранения глаза, ПХО роговицы, сквозные швы роговицы

АКТУАЛЬНІСТЬ. Проникаючі поранення рогівки складають від 52 до $70 \%$ серед усіх пошкоджень органа зору. В Україні серед травм ока, що призводять до інвалідності, проникаючі поранення займають лідируюче положення, становлячи $24,1 \%$, а серед працездатного населення - 30,1\%, що зумовлює високу медико - соціальну значимість даної патології (Аніна Є. І., Мартопляс К. В., 2008).

Одним із основних факторів, що впливають на функціональний результат, є якість проведення первинної хірургічної обробки (ПХО) травмованого ока. Метою первинної хірургічної обробки ран рогівки є усунення рани рогівки з відновленням iï цілісності та створення умов для загоєння первинним натягом. Підвищення точності відновлення усіх анатомічних співвідношень трав- мованої рогівки з формуванням найбільш тонкого рубця та зменшенням післяопераційного астигматизму, а також профілактика розвитку зрощень з райдужкою $є$ першочерговими завданнями первинної хірургічної обробки проникаючих поранень рогівки.

Мета роботи. Виявити оптимальний спосіб проведення ПХО ран рогівки шляхом порівняльного аналізу ефективності різних способів первинної хірургічної обробки проникаючих поранень рогівки.

МАТЕРІАЛ ТА МЕТОДИ ДОСЛІДЖЕННЯ. Об'єм клінічних досліджень становили 87 хворих (87 очей) з лінійними проникаючими пораненнями рогівки різної до-

(C) Н. Ф. Боброва, В. І. Шевчик, М. П. Кульбіда, 2011 